\title{
THE INFLUENCE Of LANGUAGE TRANSFER ON CONSONANT CLUSTER PRODUCTION
}

\author{
Berta Flores \\ Xinia Rodríguez
}

\begin{abstract}
The simplification of consonat clusters in word-initial, word medial, and word-final position in English is contrastively analyzed in a sample of seven Costa Rican adults. Transfer from Spaish is manifested in the systematic choice of epenthesis to simplify word-initial consonant clusters, substitution and consonant delation to deal with wordmedial clusters, and deletion, and devoicing to modify word-final clusters.
\end{abstract}

\section{Introducción}

The role of the first language has been a major issue in the field of second language acquisition (SLA). Researchers have made contrastive analyses to determine the differences between the first and second languages and then attempt to predict the errors the learner will make. Although "the strong form of the Contrastive Analysis Hypothesis" (Wardhaugh 1970) lost prestige from the late sixties until recently, CA has been revised lately with the intention of explaining the actual influence of L1 on SLA. In spite of all the arguments against the validity of contrastive analysis, it does indeed account for many transfer errors in the area of phonology. For this reason, we consider it imperative to continue research in this field to corroborate previous findings and to test new hypotheses. According to research, for example, when the syllable structure of the target language differs substantially from that of the L1, the learner experiences trouble with its pronunciation.

This paper presents the results of an investigation on the influence of language transfer on the production of consonant clusters in a sample of seven adult Spanish speakers learning English as a foreign language at the University of Costa Rica. 


\section{Theoretical Background}

\section{A. Revision of the Contrastive Analysis Hypothesis}

Cognitive psychologists as well as educators have seriously questioned contrastive analysis on the grounds of its behavioristic principles and the relative failure of its strong form. Contrastive analysis is based on the assumption that the learner transfers old habits (the patterns of the first language) when learning new habits from the second language. A first attack on this assumption comes from cognitivism which argues against viewing language acquisition as habit formation. Recent research has presented new evidence against traditional CA. Learners might experience no difficulty in areas in which the hypothesis has predicted the occurrence of transfer errors (Dulay and Burt, 1975; Richards, 1975 in Broselow, 1987). Broselow states that CA has lost its "predictive power"; however, she argues that the first language plays a very important role in SLA. Modern researchers have set out to study how contrastive analyses can contribute more to this field. Instead of abandoning CA, Broselow proposes a revision of the hypothesis in order to try to "define the subset of errors which are caused by transfer" and to "predict just what sorts of native language - target language differences will cause learners to make errors" (Broselow, 1987). Here Broselow accounts for the fact that not all the differences between the L1 and the L2 result in errors. It is necessary, then, to determine which areas become more troublesome for the learner.

Ellis (1985) comments on two forms in which the Contrastive Analysis Hypothesis has been reappraised. First, researchers revised the nature of language transfer in an attempt to specify the conditions under which the L1 interfered with the L2 and the type of L1 knowledge the learner used. The second revision was aimed at restating CA under a more cognitive framework, and the term "strategy" derived, then, from this new view.

The interest of the present study is to assess the validity of Contrastive Analysis in the field of phonology.

Dulay, Burt, and Krashen (1982) assert that CA has been useful in the prediction of a large number of phonological errors especially in adults and beginning level children. Anecdotal or observational evidence suggests that children process the sound system of the L2 through that of the L1. As children advance in the process, they use more and more target language sounds. On the contrary, a majority of adults rely heavily on the L1 sound system during most of their lives. Dulay, Burt, and Krashen point out that it is still unknown why interference affects adults more than children.

Dulay, Burt, and Krahen also consider the influence of the first language much greater in the area of phonology than in syntax. The learner builds up the L2 phonological system using L1 sounds. Therefore, CA plays a very important role in the area of phonology. At present, researchers are carrying out their studies having in mind a different view of language transfer.

\section{B. Language Transfer}

The role of the first language in L2 acquisition was very debatable in the past three decades. According to behavioral psychologists, transfer is defined as a process in which the lear- 
ner uses "past learned behaviors" in an automatic and subconscious way when attempting to produce "new responses" ( Dulay, Burt and Krashen, 1982). Thus, there may be positive or negative transfer. The former refers to the production, by the learner, of correct syntactic or phonological structures that L1 and L2 share. Negative transfer refers to the opposite case, i.e., when the learner makes an error as a result of the interference of an old behavior which is different from the new habit (Dulay, Burt, and Krashen, 1982). These linguists use the term "transfer" to describe "a characteristic of the learner's performance." They also state that it is possible to label as "transfer errors" those that have a similar structure to the L1, even if the real source of these errors may be another one.

Educational psychologists and educators have used the term "transfer" to refer to "the use of past knowledge and experience in new situations." (Dulay, Burt, and Krashen, 1982). The L2 learner uses background knowledge to cope with the new situations he encounters. These last two conceptions of transfer are based on cognitive views of second language acquisition. Cognitive psychologists now consider transfer as a learner strategy. The learner's knowledge of his first language can help in hypothesis formation (Ellis, 1985). Together with already existing L2 knowledge, the learner uses his or her L1 in order to build and test hypotheses.

Corder (1978b in Ellis, 1985) points out that the learner's L1 may facilitate second language learning when the L1 and the L2 are similar. When both languages differ, the learner substitutes L1 structures for the insufficient L2 knowledge. He states that "interference" errors are the result of "borrowing." In the area of phonology, the learner has to resort to L1 sounds in order to be able to produce utterances containing new sounds. However, research still has to account for the cases in which the native language does not influence L2 sounds. Corder proposes to restate the concept of "interference" as "intercession." As Ellis (1985) rephrases it, "Whereas interference has been traditionally seen as a feature of learning, intercession is to be considered a strategy of communication." As can be noticed, this view coincides with Dulay's, Burt's and Krahen's position regarding transfer.

In this study, the term transfer will be considered a communication strategy by means of which learners resort to a phonological structure of their first language when they have insufficient knowledge of the target phonological system.

\section{Review of Related Research Studies}

Tarone (1987) conducted a pilot study on the syllable structure of interlanguage phonology with six adult learners of English; two spoke Cantonese, two spoke Korean, and the last two spoke Brazilian Portugese. Each subject had to tell a story based on the same set of pictures. Tarone categorized the errors as epenthesis, consonant deletion, and insertion of glottal stops. According to her results, the subjects' choice of epenthesis or consonant deletion seemed to depend on their first language. Besides, language transfer appeared to be the dominant process shaping interlanguage syllable structure; however, Tarone also found other errors not traceable to the subjects' L1s. Independently of their native language, the informants showed a preference for the open syllable which is evidence of the operation of universal processes. 
Based on Tarone's study on interlanguange syllable structure, Sato (1987) investigated the interlanguages of two Vietnamese children acquiring English, in order to test previous claims about language transfer and universal processes. She collected samples of spontaneous speech from the two Vietnamese boys and classified syllable-initial and syllable-final errors as reduction, deletion or feature change. Her results supported the hypothesis about the influence of L1 transfer on the subjects' "preference for the closed syllable in the modification of English syllable-final consonant clusters" (Sato, 1980). Language transfer also determined greater or lesser degrees of difficulty in the production of initial and final consonant clusters. Sato also supported her findings with Greenber's (1983) about the influence of L1 transfer on cluster position preference.

Broselow (1983) made a study on initial consonant clusters with native speakers of Iraqi Arabic and Egyptian Arabic. She used two informants per dialect, and she found that native language rules have a strong influence on the subjects' systematic choice of a given phonological process in their attempt to simplify difficult L2 structures. In short, Broselow found evidence of transfer of the epenthesis rule from the Egyptian dialects into the structure of English initial clusters.

Finally, Broselow (1987) studied the effect of transfer on word juncture. Two of her results are relevant to this study. First, she corroborated that "transfer does play a role in second language acquisition ... in the area of phonology;" second, she concluded that "syllable structure restrictions are particularly susceptible to transfer" (Broselow, 1987). Her study was conducted under the framework of a revised Contrastive Analysis Hypothesis in an attempt to predict the kinds of errors attributable to language transfer.

In the light of all these studies, we argue that the phonological processes learners use to simplify consonant clusters in L2 depend, to a certain extent, on transfer from their native language. We expect to corroborate Sato's claim that the L1 determines the subjects' preferences in relation to cluster position. We hypothesize that word-final consonant clusters represent a bigger problem for Spanish speakers because Spanish has fewer and less complex consonant clusters than English (Stockwell and Bowell, 1970). While syllable-initial and syllable-medial clusters are permitted in Spanish, syllable-final ones are rare (Stockwell and Bowell, 1970). Besides, word-final consonant clusters are not permitted in the phonological system of Spanish.

According to the literature, the most common problem Spanish speakers face when learning English concerns initial consonant clusters with the combination of /s/ plus a consonant (sC). They tend to epenthesize /espiyk/ for "speak" (Prator and Robinett, 1967; Broselow, 1987). This phonological process conforms to the Spanish rule of inserting /e/ before word-initial sC sequences (Hyman, 1975). However, there is less research on the problems word-medial and word-final consonant clusters may present to Spanish speakers learning English.

\section{Methodology}

\section{A. Subjects}

The subjects in this study are seven second-year English majors, chosen at random out of a group of twenty. All of them are Costa Rican, three males and four females. They studied 
in a public high school and their ages range from eighteen to twenty two. They have already completed a year and a half of their major.

At the moment the study was carried out, the informants were taking the course Phonetics II. One of the main objectives of this course was to help the students achieve accurate production of segmental and suprasegmental phonemes. The informants were also taking Grammar II and Composition II. Five of the subjects reported that they spoke English in class only; the other two subjects sometimes practiced English with native speakers outside of class.

\section{B. Data Collection and Procedure}

The data were collected through audiotaping six thirty-minute sessions for two and a thirty-minute half months. Two sessions took place at the beginning of the period, two in the middle and two at the end. These three times are identified as Time 1, Time 2 and Time 3.

In each of the sessions, the students were asked to read a list of words, some sentences, and a paragraph; then they had to answer three questions about the topics discussed in their phonetics class and about themselves.

\section{Analysis}

For each subject, all the words containing consonant clusters were transcribed using the International Phonetic Alphabet. The words were grouped according to word-initial (WI), word-medial (WM) and word-final (WF) consonant clusters. Then the percentages of the errors per subject, in each position, were calculated. The next step was to calculate the percentages of the overall phonological processes each subject used in the simplification of clusters types; and the final step was to calculate the percentage of errors due to language transfer out of the total number of errors each subject made.

\section{Results}

Table 1 shows that an average of $23 \%$ of the total number of consonant clusters (363) produced by all the informants at Time 1 contain errors. At Time 2, from 618 CCs attempted, 13\% were mispronounced, and $18 \%$ of the total number of 818 consonant clusters attempted at Time 3 contain errors. There is a decrease of $10 \%$ at Time 2 but a slight increase of $5 \%$ at Time 3 .

Tables 2.1, 2.2 and 2.3 show the percentages of errors in word-initial, word-medial, and word-final consonant clusters. These three tables clearly show where most of the errors are distributed. As indicated in Table 2.1 the subjects produced the least number of errors in word-initial consonant clusters. From a total number of 128 consonant clusters attempted at Time 1 , the average number of errors is $4 \%$ which decreases to $2 \%$ at Time 2 and increases again to $6 \%$ at Time 3. According to these results, all subjects had less trouble with the production of WI consonant clusters. Actually, six of the informants made no errors at one time or another. 


\section{TABLE 1}

Overall Percentage of Consonant Cluster Errors

\begin{tabular}{|c|c|c|c|c|c|c|c|c|c|}
\hline \multirow[b]{2}{*}{ Subject } & \multicolumn{2}{|c|}{ Time 1} & \multirow[b]{2}{*}{$\%$} & \multicolumn{2}{|c|}{ Time 2} & \multirow[b]{2}{*}{$\%$} & \multicolumn{2}{|c|}{ Time 3} & \multirow[b]{2}{*}{$\%$} \\
\hline & $\mathrm{CCs}$ & errors & & CCs & errors & & CCs & errors & \\
\hline 1 & 44 & 16 & $36 \%$ & 72 & 13 & $18 \%$ & 94 & 16 & $17 \%$ \\
\hline 2 & 66 & 08 & $12 \%$ & 55 & 05 & $9 \%$ & 64 & 10 & $16 \%$ \\
\hline 3 & 64 & 14 & $22 \%$ & 78 & 00 & & 94 & 09 & $10 \%$ \\
\hline 4 & 38 & 08 & $21 \%$ & 95 & 07 & $7 \%$ & 94 & 06 & $6 \%$ \\
\hline 5 & 41 & 05 & $12 \%$ & 91 & 01 & $1 \%$ & 94 & 06 & $6 \%$ \\
\hline 6 & 55 & 19 & $35 \%$ & 100 & 24 & $24 \%$ & 200 & 53 & $27 \%$ \\
\hline 7 & 55 & 15 & $27 \%$ & 127 & 30 & $23 \%$ & 178 & 51 & $29 \%$ \\
\hline Total & 363 & 85 & $23 \%$ & 618 & 80 & $13 \%$ & 818 & 151 & $18 \%$ \\
\hline
\end{tabular}

TABLE 2.1

Percentage of Errors in WI Consonant Clusters

\begin{tabular}{|c|c|c|c|c|c|c|c|c|c|}
\hline \multirow[b]{2}{*}{ Subjects } & \multicolumn{2}{|c|}{ Time 1} & \multirow[b]{2}{*}{$\%$} & \multicolumn{2}{|c|}{ Time 2} & \multirow[b]{2}{*}{$\%$} & \multicolumn{2}{|c|}{ Time 3} & \multirow[b]{2}{*}{$\%$} \\
\hline & CCs & errors & & $\mathrm{CCs}$ & errors & & $\mathrm{CCs}$ & errors & \\
\hline 1 & 08 & 01 & $13 \%$ & 22 & 00 & & 22 & 02 & $9 \%$ \\
\hline 2 & 21 & 00 & & 24 & 02 & $8 \%$ & 15 & 00 & \\
\hline 3 & 37 & 01 & $3 \%$ & 24 & 00 & & 22 & 01 & $5 \%$ \\
\hline 4 & 12 & 01 & $8 \%$ & 24 & 00 & & 22 & 01 & $5 \%$ \\
\hline 5 & 10 & 01 & $10 \%$ & 26 & 00 & & 22 & 00 & \\
\hline 6 & 20 & 01 & $5 \%$ & 30 & 01 & $3 \%$ & 41 & 07 & $17 \%$ \\
\hline 7 & 20 & 00 & & 26 & 00 & & 26 & 00 & \\
\hline Total & 128 & 05 & $4 \%$ & 176 & 03 & $2 \%$ & 170 & 11 & $6 \%$ \\
\hline
\end{tabular}

TABLE 2.2

Percentage of Errors in WM Consonant Cluster

\begin{tabular}{lccccccccc}
\hline & \multicolumn{2}{c}{ Time 1 } & \multicolumn{2}{c}{ Time 2 } & \multicolumn{3}{c}{ Time 3 } \\
Subject & CCs & errors & $\%$ & CCs & errors & $\%$ & CCs & errors & $\%$ \\
\hline 1 & 15 & 05 & $33 \%$ & 11 & 02 & $18 \%$ & 26 & 03 & $12 \%$ \\
2 & 15 & 02 & $13 \%$ & 10 & 00 & & 24 & 06 & $25 \%$ \\
3 & 08 & 03 & $38 \%$ & 14 & 00 & & 26 & 04 & $15 \%$ \\
4 & 09 & 02 & $22 \%$ & 17 & 00 & & 26 & 01 & $4 \%$ \\
5 & 18 & 03 & $17 \%$ & 20 & 01 & $5 \%$ & 26 & 01 & $4 \%$ \\
6 & 11 & 05 & $45 \%$ & 20 & 01 & $5 \%$ & 57 & 15 & $26 \%$ \\
7 & 11 & 05 & $45 \%$ & 46 & 04 & $9 \%$ & 65 & 26 & $40 \%$ \\
\hline Total & 87 & 25 & $29 \%$ & 138 & 08 & $6 \%$ & 250 & 56 & $22 \%$ \\
\hline
\end{tabular}


In relation to word-medial consonant clusters, we can see in Table 2.2 that the average percentages of errors at each time are higher than those of word-initial consonant clusters. The average of errors at Time 1 is $29 \%$, decreasing to $6 \%$ and then increasing to $22 \%$ at Times 2 and 3 .

TABLE 2.3

Percentage of Errors in WF Consonant Clusters

\begin{tabular}{lccccccccc}
\hline & \multicolumn{2}{c}{ Time 1 } & \multicolumn{2}{c}{ Time 2 } & \multicolumn{3}{c}{ Time 3 } \\
Subject & CCs & errors & $\%$ & CCs & errors & $\%$ & CCs & errors & $\%$ \\
\hline 1 & 21 & 10 & $48 \%$ & 39 & 11 & $28 \%$ & 46 & 11 & $24 \%$ \\
2 & 30 & 06 & $20 \%$ & 21 & 03 & $14 \%$ & 25 & 04 & $16 \%$ \\
3 & 19 & 10 & $53 \%$ & 40 & 00 & & 46 & 04 & $9 \%$ \\
4 & 17 & 05 & $29 \%$ & 54 & 07 & $13 \%$ & 46 & 04 & $9 \%$ \\
5 & 13 & 01 & $8 \%$ & 45 & 00 & & 46 & 05 & $11 \%$ \\
6 & 24 & 13 & $54 \%$ & 50 & 22 & $44 \%$ & 102 & 31 & $30 \%$ \\
7 & 24 & 10 & $42 \%$ & 55 & 26 & $47 \%$ & 87 & 25 & $29 \%$ \\
\hline \multirow{2}{*}{ Total } & 148 & 55 & $37 \%$ & 304 & 69 & $23 \%$ & 398 & 84 & $21 \%$ \\
\hline
\end{tabular}

Table 2.3 shows a definite increase in WF consonant cluster errors. However, it is noticeable that the percentage of errors decreases at Times 2 and 3; from an average of $37 \%$ at Time 1, the percentage of errors decreases to $23 \%$ and $21 \%$ at Times 2 and 3, respectively.

The next step in the analysis of the results concerns the overall use of particular phonological processes in the simplification of consonant clusters.

Table 3.1 gives the figures corresponding to WI clusters.

TABLE 3.1

Overall Phonological Processes Preferred in the Simplification of Initial Consonant Clusters

$\begin{array}{llll}\text { Subjects } & \text { Epenthesis } & \text { Deletion } & \text { Total \# of errors }\end{array}$

\begin{tabular}{|c|c|c|c|c|c|c|c|c|}
\hline 1 & 02 & $67 \%$ & 01 & $33 \%$ & 0 & & 03 & \\
\hline 2 & 02 & $100 \%$ & 0 & & 0 & & 02 & \\
\hline 3 & 01 & $50 \%$ & 01 & $50 \%$ & 0 & & 02 & \\
\hline 4 & 01 & $50 \%$ & 01 & $50 \%$ & 0 & & 02 & \\
\hline 5 & 0 & & 01 & $100 \%$ & 0 & & 01 & \\
\hline 6 & 06 & $67 \%$ & 02 & $22 \%$ & 01 & $11 \%$ & 09 & \\
\hline 7 & 0 & & 0 & & 0 & & 00 & \\
\hline Total & 12 & $63 \%$ & 06 & $32 \%$ & 01 & $5 \%$ & 19 & $100 \%$ \\
\hline
\end{tabular}


The subjects rely mostly on epenthesis, followed by substitution and deletion for the modification of WI consonant clusters, in the proportions: $63 \%$ for epenthesis, $32 \%$ for substitution and $5 \%$ for deletion.

The use of epenthesis in WI consonant clusters can be traced to the first language. Spanish has the rule of inserting a vowel sound /e/ before word-initial $\mathrm{sC}$ sequences, as was stated above (Hyman, 1975).

When the subjects tried to produce WI clusters, they made errors like the following:

[estarts] for [starts] (starts)

[espr in] for [sprin] (spring)

The subjects also made substitution errors induced by the spelling of the word and not by language transfer. For instance, instead of [sfiyər], two subjects said [spyiər] (sphere).

Table 3.2 presents the phonological processes involved in the simplification of WM consonant clusters.

TABLE 3.2

Overall Phonological Processes Preferred in the Simplification of Medial Consonant Clusters

\begin{tabular}{|c|c|c|c|c|c|c|c|c|c|}
\hline \multirow{2}{*}{$\begin{array}{c}\text { Subject } \\
1\end{array}$} & \multicolumn{2}{|c|}{ Substitution } & \multicolumn{2}{|c|}{ Deletion } & \multicolumn{2}{|c|}{ Overgeneralization } & \multicolumn{2}{|c|}{ Devoicing } & Errors \\
\hline & 05 & $40 \%$ & 04 & $40 \%$ & 01 & $10 \%$ & 0 & & 10 \\
\hline 2 & 04 & $50 \%$ & 00 & & 00 & & 04 & $50 \%$ & 08 \\
\hline 3 & 04 & $57 \%$ & 01 & $14 \%$ & 01 & $14 \%$ & 01 & $14 \%$ & 07 \\
\hline 4 & 02 & $67 \%$ & 01 & $33 \%$ & 00 & & 00 & & 03 \\
\hline 5 & 01 & $20 \%$ & 03 & $60 \%$ & 01 & $20 \%$ & 00 & & 05 \\
\hline 6 & 07 & $29 \%$ & 08 & $33 \%$ & 04 & $14 \%$ & 02 & $10 \%$ & 21 \\
\hline 7 & 14 & $37 \%$ & 16 & $43 \%$ & 04 & $9 \%$ & 01 & $3 \%$ & 35 \\
\hline Total & 37 & $42 \%$ & 33 & $37 \%$ & 11 & $12 \%$ & 08 & $10 \%$ & 89 \\
\hline
\end{tabular}

The predominant phonological processes in WM consonant clusters are substitution $42 \%$ and deletion $37 \%$. The other processes are overgeneralization $12 \%$ and devoicing $9 \%$. Although devoicing is a subcategory of substitution, it is included separately because of the large number of errors that involve this particular process, especially in WF consonant clusters.

The most common case of devoicing in word-medial CCs was the substitution of the cluster [gz] for [ks] as in the words "example" and "exist." Since the letter " $\mathrm{x}$ " is pronounced as $[\mathrm{ks}]$ in Spanish, the devoicing of [gz] may be traced to the L1.

Finally, Table 3.3 shows the phonological processes used to modify WF consonant clusters. 


\section{TABLE 3.3}

Overall Phonological Processes Preferred in the Simplification of Final Consonant Clusters

\begin{tabular}{|c|c|c|c|c|c|c|c|c|c|c|c|}
\hline \multicolumn{2}{|l|}{ Subject } & Substit. & \multicolumn{2}{|c|}{ Delet. } & \multicolumn{2}{|c|}{ Overgen. } & \multicolumn{2}{|c|}{ Devoic. } & \multicolumn{2}{|c|}{$\begin{array}{l}\text { Metathesis } \\
\text { of errors }\end{array}$} & Total \# \\
\hline 1 & 04 & $13 \%$ & 10 & $31 \%$ & 04 & $13 \%$ & 13 & $40 \%$ & 01 & $3 \%$ & 32 \\
\hline 2 & 05 & $38 \%$ & 01 & $8 \%$ & 00 & & 07 & $54 \%$ & 00 & & 13 \\
\hline 3 & 00 & & 01 & $7 \%$ & 00 & & 13 & $93 \%$ & 00 & & 14 \\
\hline 4 & 00 & & 03 & $19 \%$ & 01 & $6 \%$ & 12 & $75 \%$ & 00 & & 16 \\
\hline 5 & 00 & & 00 & & & & 01 & & 05 & $83 \%$ & 06 \\
\hline 6 & 04 & $6 \%$ & 22 & $33 \%$ & 15 & $23 \%$ & 24 & $36 \%$ & 01 & $2 \%$ & 66 \\
\hline 7 & 07 & $11 \%$ & 16 & $26 \%$ & 01 & $2 \%$ & 32 & $52 \%$ & 05 & $8 \%$ & 61 \\
\hline Total & 21 & $10 \%$ & 53 & $25 \%$ & 21 & $10 \%$ & 102 & $49 \%$ & 12 & $6 \%$ & 208 \\
\hline
\end{tabular}

The predominant process in WF clusters is devoicing with an average of errors of $49 \%$. The informants transferred the final [s] of Spanish to produce the following:

[frends] instead of [frendz] (friends)

In order of importance of occurrence, the second process is deletion used in $25 \%$ of the total number of errors made. As was mentioned before, the phonological system of Spanish does not allow WF consonant clusters and coincidentally, the deletion of one member of a word-final consonant cluster was very common:

[wArldz] was pronounced as [wArds]

[əf\&kts] was pronounced as [ $\mathrm{ffts}$ ]

In both cases the first consonant of the cluster was deleted. When the informants had to say a word whose pronunciation is very similar to the same word in Spanish, they got rid of the troublesome consonant in the cluster by producing a closer approximation of the pronunciation of the word in Spanish.

[Esєpšən] for " exception," where the phoneme [k] is deleted.

[ æseptəbəl] for "acceptable", again the sound [k] is deleted.

The overgeneralization of phonological rules cannot be traced to Spanish and could instead be attributed to developmental processes or to overmonitoring. 
The final significant process is Metathesis, $6 \%$ used by four of the subjects. This process is not the result of language transfer either.

As can be observed comparing the three tables, the subjects use more phonological processes to simplify WF clusters. Besides, they make 208 errors in WF clusters, as opposed to 89 in WM and 19 in WI ones.

The following table shows the percentage of errors caused by language transfer.

Table 4

Processes Underlying Consonant Cluster Errors

\begin{tabular}{ccccc}
\hline Subject & \# of errors & $\begin{array}{c}\text { \# of errors due to } \\
\text { language transfer }\end{array}$ & \# of Non-transfer & errors \\
\hline & 45 & 35 & $78 \%$ & 10 \\
2 & 23 & 12 & $52 \%$ & 11 \\
3 & 23 & 14 & $61 \%$ & 09 \\
4 & 21 & 19 & $90 \%$ & 03 \\
5 & 12 & 09 & $75 \%$ & 32 \\
6 & 96 & 64 & $67 \%$ & 44 \\
7 & 96 & 52 & $54 \%$ & 111 \\
\hline
\end{tabular}

According to Table 4, most of the errors made by each of the subjects are the result of language transfer. An average of 65 percent of the errors can be attributed to the influence of the Spanish phonological system.

However, there is also a considerable number of non-transfer errors. Some of these are perhaps caused by developmental or universal processes. The present study did not seek to analyze non-transfer errors, but a list of some of these errors is presented in the appendix as material for further research.

\section{Discussion}

We had argued that the phonological processes learners use to simplify consonant clusters depend mainly on language transfer. The results of this study confirm this hypothesis since the subjects systematically chose one or more specific processes to modify the consonant clusters in all three positions.

In the case of WI clusters, the subjects clearly favored epenthesis over other processes. This constitutes evidence to assert that learners rely on their L1 when encountering sC structures. However, it is important to point out that this error was not as prevalent as was expected; in fact, two of the subjects made no epenthesis errors at all.

In relation to WM clusters, the subjects systematically chose substitution and consonant deletion, and regarding WF clusters, they favored consonant deletion and devoicing. 
As the students used specific phonological processes in each of the positions, the influence of transfer is evident. Otherwise, they probably would have employed different processes when dealing with the same type of clusters.

Secondly, we attempted to corroborate Sato's claim (1987) that the learner's preferences in relation to cluster position are influenced by the L1. According to this assertion, Spanish learners would have more trouble producing English WF clusters. In fact, the subjects had more non-target $\dot{W F}$ clusters, which confirms previous findings. Besides producing a higher number of errors in WF clusters, the subjects also used a wider variety of phonological processes for their modification. Such evidence suggests that Spanish learners have to work harder in the accurate production of WF consonant clusters.

Finally, comparing the production of errors at each time, the subjects made fewer errors at Times 2 and 3, in general. There was a slight increase at Time 3 in WI and WM CCs errors.

\section{Conclusions}

This study has presented evidence to support the following assertions:

1. Language transfer constitutes an important strategy in the simplification of consonant clusters, thus confirming Sato's (1987) and Tarone's (1987) findings.

2. Specifically, transfer from Spanish is manifested in the systematic choice of the following phonological processes: epenthesis for WI consonant clusters, substitution and consonant deletion for WM clusters and consonant deletion and devoicing for WF ones.

3. Spanish also influences the subjects' greater difficulty in the production of WF clusters.

\section{Implications}

As modern researchers consider language transfer a strategy of communication, educators have to be careful with the correction of pronunciation errors. Teachers should keep in mind that the first language constitutes background knowledge that helps learners to communicate in the second language.

Instructors have to provide enough input coming from varied sources so that students can acquire the new phonological system. Besides this, learners also need to be aware of the errors they make and the differences between L1 and L2. Closer approximations to the native accent, with instances of backsliding, will be made by the students if errors are taken as a tool to build up and not to destroy.

Since final consonant clusters are more difficult for Spanish speakers learning English, special activities have to be included in the outline of a Phonetics course. If the aim is both fluency and accuracy, the two areas need to be tackled. Of course, caution in error correction is needed to prevent overmonitoring. By exposing the students to native or native-like pronunciation through movies, radio programs, songs and class visitors, teachers may guarantee quality input. Besides, if the affective filter in the classroom is low enough, there are more chances of preventing avoidance when the structure is too difficult for the student to deal with. 
If instructors do not provide the necessary quantity and quality of input and if students do not practice the L2 outside of class, they might run the risk of ending up with fossilized errors.

\section{Suggestions for further research}

As was suggested above, the non-transfer errors need to be analyzed in order to account for their cause.

Contrastive Analysis has to undergo further revision too, as Broselow (1987) proposes. The field of second language acquisition can benefit still more if the CA Hypothesis results more accurate in its predictions.

Consonant cluster production is one of the areas in which the learner is very likely to resort to the $\mathrm{L} 1$; more investigation has to be done in other important areas.

Finally, task variation and style (careful or vernacular) are two important factors to be taken into account when eliciting the corpus since they are closely related to the production of phonological errors. A variety of tasks was used in the present study and seemed to influence the results to a certain extent. It would be very interesting to compare results obtained when using only one type of task (free conversation, for example).

\section{Appendix: sample list of non-transfer errors}

Target sequence

[signffıkənt]
[wərk]
[skriynz]
[dıv́́ləpmєnts]
[ædəlesəns]
[organz]
[rızəlts]
[gırlz]

IL sequence

[sinífiykant]

[wərt]

[eskriyms]

[dıv $\in \mathrm{l} \supset \mathrm{pm} \in \mathrm{ms}$ ]

[æd $\partial \mathrm{l} \epsilon \mathrm{s} \partial \mathrm{ms}$ ]

[orgams]

[rIs $\supset 1 p s]$

[gərts]
Permissible Phonological process

[signifikativo]
none
none
none
none
none
none
none

Deletion Substitution Substitution Substitution Substitution Substitution Substitution Substitution

\section{Selected Bibliography}

Altenberg and Vago. 1987. "Theoretical Implications of an Error Analysis of Second Language Phonology Production.” In G. Ioup and S. H. Weinberger (Eds.) Interlanguage Phonology and the Acquisition of a Second Language System. Cambridge: Newbury House Publishers. 
Anderson, S. 1974. The Organization of Phonology. New York: Academic Press, Inc.

Broselow, E. 1983. "Non-Obvious Transfer: On Predicting Epenthesi Errors.” In Georgette Ioup and S.H. Weinberger (Eds.) Interlanguange Phonology and the Acquisition of a Second Language System. Cambridge: Newbury House Publishers.

. 1987. "An Investigation of Transfer in Second Language Phonology." In Geogette Ioup and S. H. Weinberger (Eds.) Interlanguage Phonology and the Acquisition of a Second Language System. Cambridge: Newbury House Publishers.

Dulay, H., Burt, M., and S. Krashen, 1982. Language Two. New York: Oxford University Press.

Eckman, Fred. 1987 "On the Naturalness of Interlanguage Phonological Rules." In Georgette Ioup and S.H. Weinberger (Eds.) Interlanguage Phonology and the Acquisition of a Second Language System. Cambridge: Newbury House Publishers, Inc.

Ellis, R. 1987. Understanding Second Language Acquisition. Oxford: Oxford University Press.

Fledge, E. 1981. “The Phonological Basis of Foreign Accent: A Hypothesis.” TESOL Quarterly 15: 443-55.

Gass. S. and Larry Selinker. 1983. Language Transfer in Language Learning. Mass.: Newbury House Publishers, Inc.

Hatch, E. 1978. Second Language Acquisition. Rowley, Mass.: Newbury Howse Publishers.

Hetch, B. and Randa Mulford. 1987. "The Acquisition of a Second Language Phonology. Interaction of Transfer and Developmental Factors." In Georgette Ioup and S.H. Weinberger (Eds.) Interlanguage Phonology and the Acquisition of a Second Language System. Cambridge: Newbury House Publishers, Inc.

Hyman, L. 1975. Phonology: Theory and Analysis. New York: Holt, Rinehart and Winston.

Ioup, G. and S.H. Weinberger, 1987. Interlanguage Phonology and the Acquisition of a Second Language System. Cambridge: Newbury House Publishers.

Odlin, Terence. 1989. Language Transfer. Cross-Linguistic Influence in Language Learning. Cambridge: Cambridge University Press.

Richards, J. 1974. “A Non-Contrastive Approach to Error Analysis.” In Richards, Jack (Ed.) Error Analysis: Perspectives on Second Language Acquisition. London: Longman Group Limited. 
1974. "Error Analysis and Second Language Strategies." In Schuman, John and Nancy Stenson (Eds.) New Frontiers in Second Language Learning. Mass.: Newbury House Publishers, Inc.

Sato, C. 1987. "Phonological Processes in Second Language Acquisition: Another Look at Interlanguage Syllable Structure." In Georgette Ioup and Steven H. Weingberger (Eds.) Interlanguage Phonology. Mass: Newbury House Publishers.

Sridhar, S. 1980. "Contrastive Analysis, Error Analysis and Interlanguage: Three Phases of One Goal." In K. Croft (Ed.) Readings on English as a Second Language. Mass.: Winthrop Publishers, Inc.

Stockwell, Robert and Donald Bowen. 1970. The Sounds of English and Spanish. Chicago: The University of Chicago Press.

Tarone, E. 1987. "Some Influence on the Syllable Structure of Interlanguage Phonology." In Ioup G. and Weinberger S. H. Interlanguage Phonology and the Acquisition of a Second Language System. Cambridge: Newbury House Publishers.

Wardhaugh, R. 1974. "The Contrastive Analysis Hypothesis." In Schumann and Stenson (Eds.) New Frontiers in Second Language Learning. Mass.: Newbury House. 